\title{
Effects of vertical loading on lateral screw pile performance
}

1 Therar A. Al-Baghdadi BSC, MSC PhD Candidate, Civil Engineering, University of Dundee, Dundee, Scotland (corresponding author: t.albaghdadi@dundee.ac.uk)

2 Michael J. Brown BEng, PhD

Reader, Civil Engineering, University of Dundee, Dundee, Scotland
3 Jonathan A. Knappett MEng, PhD

Reader, Civil Engineering, University of Dundee, Dundee, Scotland

4 Asad H. Al-Defae BSc, MSc, PhD

Research Associate, Civil Engineering, University of Dundee, Dundee, Scotland
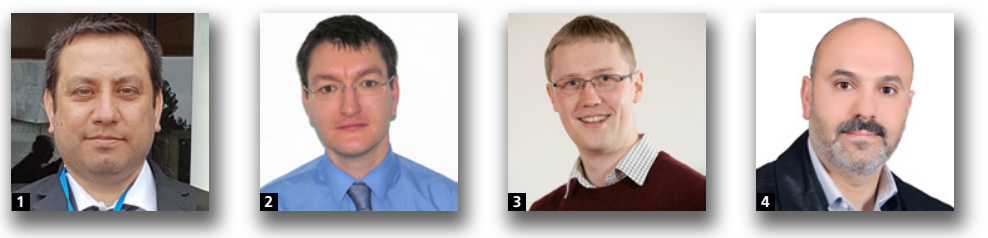

The offshore wind energy sector faces new challenges as it moves into deeper water deployment. To meet these challenges, new and efficient foundation solutions are required. One potential solution is to upscale onshore screw piles but they require verification of performance for new geometries and demanding loading regimes. This paper presents a three-dimensional finite-element analysis investigation of screw pile behaviour when subjected to combined vertical and lateral loading in sand. In the investigation, the screw pile length and helical plate diameter were varied on piles with a fixed core diameter while subjecting the piles to combined axial and lateral loading. The results were compared with results from straight shafted piles with the same core diameter. The results of the analysis revealed that vertical compression loads increased the lateral capacity of the screw piles whereas vertical uplift loads marginally reduced the lateral capacity. The downside of this enhanced lateral capacity is that the screw piles experience higher bending moments. This suggests that, when using screw piles for offshore foundation applications, structures should be designed to maintain axial compressive loads on the piles and induced bending moments need to be adequately assessed when deciding on appropriate structural sections.

\section{Notation}

$A_{\mathrm{p}} \quad$ cross-sectional area of tubular pile shaft

$D_{\mathrm{h}} \quad$ helical plate diameter

$D_{\mathrm{p}} \quad$ pile outer shaft or core diameter

$D_{\mathrm{r}} \quad$ sand relative density

$E_{\mathrm{p}} \quad$ Young's modulus of steel

$H \quad$ lateral load

$H_{\mathrm{o}} \quad$ ultimate lateral capacity

$I_{\mathrm{p}} \quad$ moment of inertia of tubular pile shaft

$K \quad$ passive earth pressure coefficient due to pile movement

$K_{\mathrm{p}} \quad$ passive earth pressure coefficient

$L \quad$ pile length

$L_{\mathrm{a}} \quad$ distance between the top and bottom helical plates

$S \quad$ spacing between helical plates

$t_{\mathrm{h}} \quad$ helical plate thickness

$t_{\mathrm{p}} \quad$ pile shaft wall thickness

$V \quad$ vertical load

$V_{\text {c,ult }} \quad$ ultimate compression capacity

$V_{\mathrm{t}, \text { ult }} \quad$ ultimate tension capacity

y lateral displacement

$z \quad$ axial displacement

$\delta^{\prime} \quad$ sand-pile interface friction angle

$\theta \quad$ pile head rotation angle

$\sigma_{\mathrm{r}}^{\prime} \quad$ radial effective stress

$\phi^{\prime} \quad$ sand friction angle

\section{Introduction}

In the UK, offshore wind turbine developments to date have predominantly been founded on large-diameter driven openended steel piles (monopiles) in water depths up to $\sim 30 \mathrm{~m}$. However, the round III wind farm sites are located in areas with water depths of up to $80 \mathrm{~m}$, which may be considered beyond the limits of cost-effective monopile deployment. This has resulted in the need for alternative foundation and sub-sea structure solutions such as jackets or tripods supported on more standard offshore foundation solutions such as multiple smaller-diameter driven piles. Based on the typical nature of a wind farm development with potentially hundreds of turbines being installed, this may result in the need to drive significant numbers of piles over a prolonged period of time. In certain areas of European regional waters this has led to concerns over the impact on marine mammals, resulting in a ban on driven piling unless costly mitigation techniques are deployed (i.e. bubble curtains or hard barrier systems) (Saleem, 2011; Thomsen et al., 2006).

One potential alternative technology that is known for enhanced axial resistance and has low noise/vibration installation is the screw anchor or screw pile. These piles typically consist of a relatively small-diameter central pile core that connects together a series of (or single) inclined helical plates (or 
flanges) that are used to screw the pile into the ground. This technique, which is used regularly onshore, has its origins in near-shore applications such as founding systems for Victorian lighthouses (Perko, 2009). Although the system is used onshore with typical pile helical plate diameters $\left(D_{\mathrm{h}}\right)$ varying up to $1016 \mathrm{~mm}$ and pile core or shaft diameters $\left(D_{\mathrm{p}}\right)$ up to $508 \mathrm{~mm}$ (Sakr, 2010b), the piles would have to upscale significantly to meet the loading demands of offshore application. This would particularly be the case for lateral pile loading as the current small core diameters used onshore have limited bending moment capacity. However, in reality, piles for any offshore jacket structure are likely to be subjected to combined axial loading (the permanent and operating loads of the turbine and any onboard equipment), lateral loading (environmental loads such as wind and waves) and moment loading. In a jacket or tripod configuration, with careful design of the pile-jacket connection, the moment load can be carried principally in additional tension and compression in horizontally spaced piles, which would suit the performance of screw piles under axial loading.

Much research has been carried out to investigate the behaviour of piles under pure lateral loads (e.g. Matlock and Reese, 1960; Poulos, 1971; Poulos and Davis, 1980; Sanctis and Russo, 2008). Other studies have also investigated how piles behave to support onshore structures under inclined loads (Meyerhof and Yalcin, 1993; Sastry and Meyerhof, 1994). The effect of a vertical load on pile lateral capacity and the pile response under combined axial and lateral loads has been investigated widely for straight shafted piles (SSPs), as summarised by Lee et al. (2011), with the obtained varying results depending on whether or not theoretical or experimental studies were carried out. For instance, the summary provided by Lee et al. (2011) suggests that for theoretical studies on driven piles installed in sand it is typical to obtain increased deflection and bending moments with only the study of Karthigeyan et al. (2006) predicting decreased deflections, although this was for non-displacement piles. Early experimental studies typically suggest decreased lateral pile deflections in the presence of vertical loading. This is in contrast to the $1 \mathrm{~g}$ model testing of SSPs driven into sand by Lee et al. (2011) who found that the presence of vertical loads reduced the capacity by $31 \%$, $14 \%$ and $7 \%$ in dense, medium dense and loose sand respectively. A review of more recent papers concerned with numerical modelling (Karthigeyan, 2008; Karthigeyan et al., 2007; Rajagopal and Karthigeyan, 2008; Zadeh and Kalantari, 2011) indicates that the presence of axial compression loads resulted in an increase in lateral capacity in sands and reduced lateral capacity in clay for wished-in-place piles. A limited number of model testing studies by Anagnostopoulos and Georgiadis (1993), Madhusudan Reddy and Ayothiraman (2015) and Mu et al. (2015) again showed an increase in capacity for both driven and wished-in-place piles in sand but reduced capacity in clay. No such similar study has been undertaken for screw piles where the presence of axial compressive loads may be envisaged to increase lateral pile capacity due to increased mobilisation of the helical plates and constraint of near-surface mechanisms during lateral pile deflection. Al-Baghdadi et al. (2015) conducted a limited numerical study investigating the effect of nearsurface screw pile helical plates on pure lateral performance but found that the effect was limited, with up to a $20 \%$ improvement in lateral capacity for a large displacement $\left(0 \cdot 1 D_{\mathrm{p}}\right)$ but only if the pile helical plates were placed close to the soil surface, thus exposing them to the effects of scour and potentially removing any enhancement.

This paper reports on an investigation into the performance of scaled-up screw piles under combined lateral and vertical load in sand using three-dimensional finite-element analysis (3D FEA). Two screw pile lengths $(L)$ were investigated (5 and $20 \mathrm{~m})$ with pile helical plate diameters $\left(D_{\mathrm{h}}\right)$ ranging from 1.5 to $2.5 \mathrm{~m}$ (with helical plates spaced at $S=1.75 \mathrm{~m}$ for $D_{\mathrm{h}}=1.5 \mathrm{~m}$ and $S=3.5 \mathrm{~m}$ for both $D_{\mathrm{h}}=2.0 \mathrm{~m}$ and $2.5 \mathrm{~m}$; $S / D_{\mathrm{h}}<2 \cdot 0$ ) subject to combined vertical (tension and compression) and horizontal loading (Figure 1). The ratio $S / D_{\mathrm{h}}<2 \cdot 0$ was selected for investigation to guarantee a cylindrical shearing/soil-soil mechanism where soil is effectively trapped between the helical plates; this has been shown to occur at $S / D_{\mathrm{h}}<3.0$ (Knappett et al., 2014). The two pile lengths were chosen to highlight the effects of long- and shortpile failure mechanisms on screw pile behaviour. The results were compared with data on SSP performance. All the piles had the same core diameter of $D_{\mathrm{p}}=750 \mathrm{~mm}$. The primary purpose of the FE models was to determine how the variation of vertical load affects lateral screw pile capacity.

\section{Numerical modelling}

The FEA suite Plaxis 3D AE was used to investigate the screw pile behaviour under axial, lateral and combined loading in comparison with SSPs (with the same shaft diameter, $\left.D_{\mathrm{p}}=750 \mathrm{~mm}\right)$ in saturated dense sand $\left(D_{\mathrm{r}}=80 \%\right)$. The study focused on dense sand, as Byrne and Houlsby (2003) reviewed many different locations released for the first phase of wind farms (round I) around the UK and it was found that the ground consists mainly of sandy soil.

\subsection{Modelling approach}

The SSPs and screw piles were modelled using 3D FEA based on the assumption of symmetry about the vertical plane in order to reduce element numbers and calculation time. Thus, only half of the pile was modelled and the screw pile helical plate inclination was ignored, with the helical plates modelled as horizontal plates to reduce the complexity of model construction. The model vertical boundaries were set to 60 times the pile shaft diameter $\left(D_{\mathrm{p}}\right)$ in each direction from the pile centreline in order to be compatible with minimal lateral separation specified in other similar studies (i.e. Bolton et al., 1999; Phillips and Valsangkar, 1987), whereas the base of the model was extended to eight times the screw pile helical plate diameter $\left(D_{\mathrm{h}}\right)$ below the pile tip for all the models, as verified by Knappett et al. (2016) (Figure 2). The top boundary was free to move in all directions whereas the bottom boundary was 


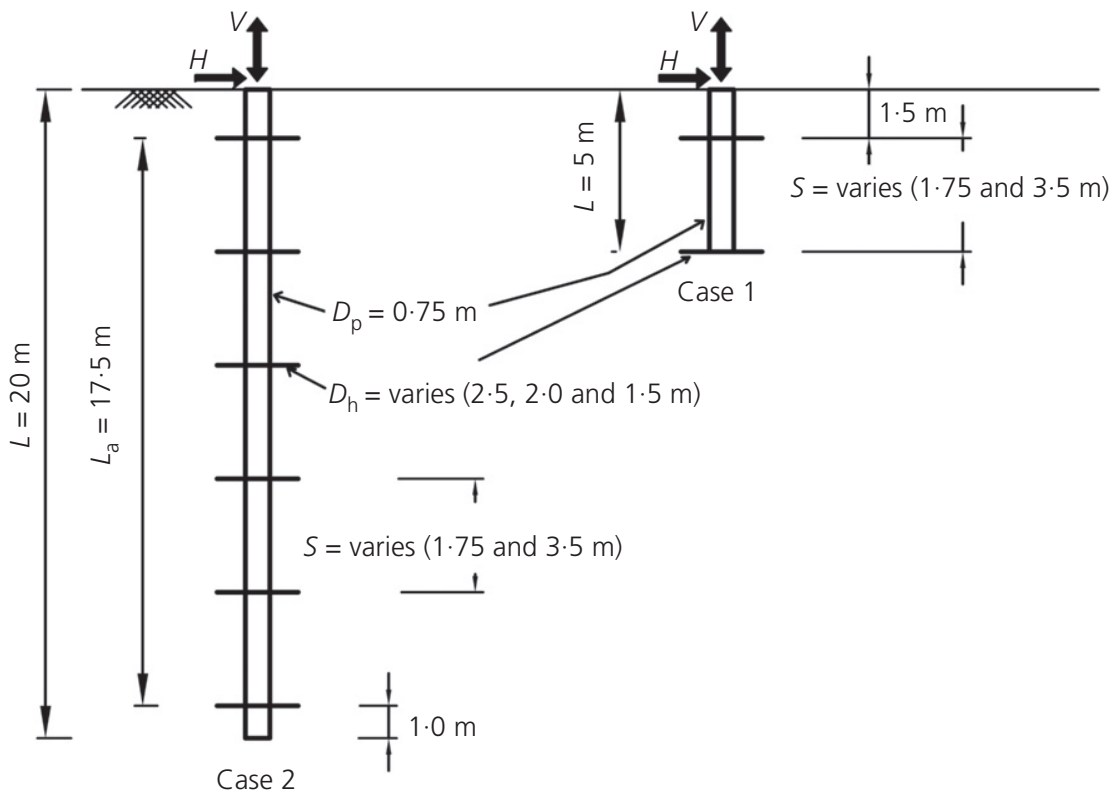

Figure 1. Screw pile geometry for the $5 \mathrm{~m}$ length (case 1) and $20 \mathrm{~m}$ length (case 2)

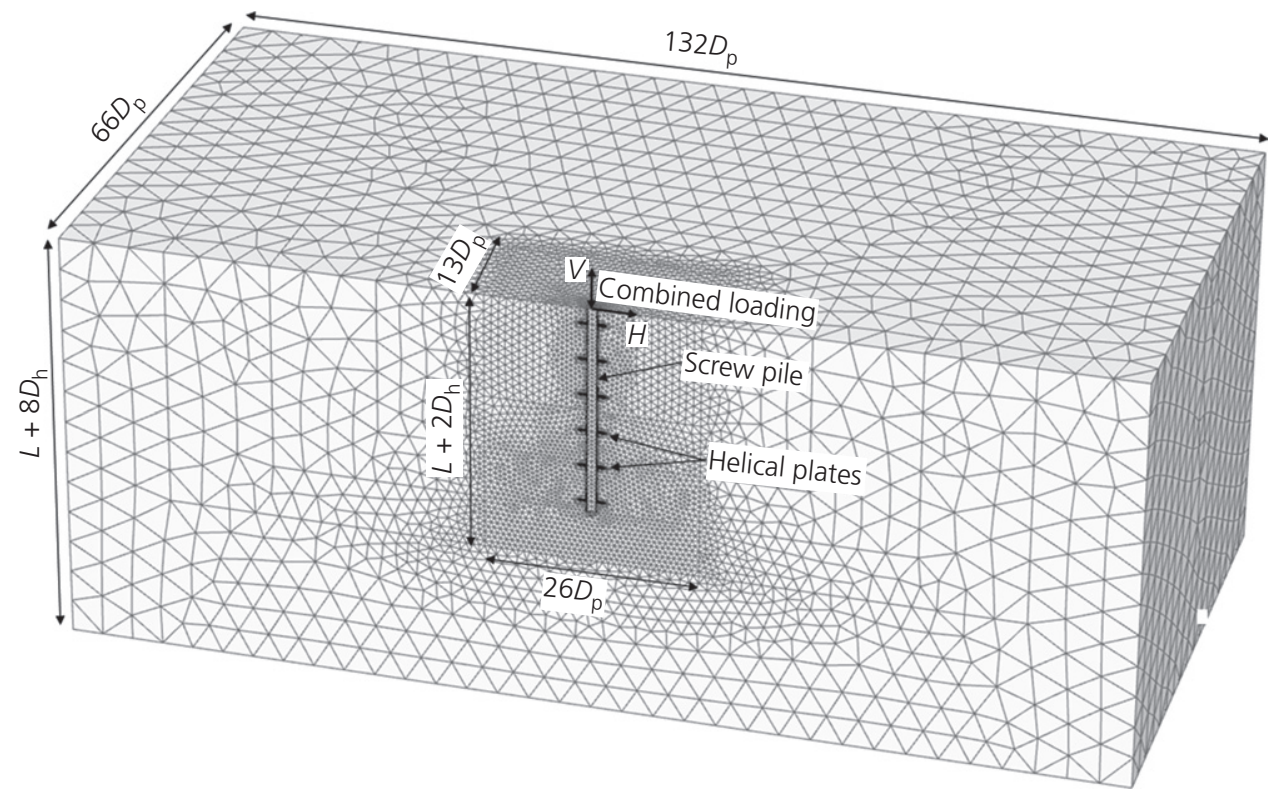

Figure 2. Typical mesh generated for screw pile modelling in 3D FEA

fully fixed and the vertical side boundaries were allowed only vertical deformation.

The core/shaft of each pile was initially modelled as a solid section with linear elastic non-porous material with equivalent axial stiffness $(E A)_{\mathrm{eq}}$ as shown in Equation 1 and equivalent bending stiffness $(E I)_{\mathrm{eq}}$ as shown in Equation 2, as a tubular section of wall thickness $10 \mathrm{~mm}$ for axial and combined loading respectively referred to as a 'volume pile' with tennode tetrahedral elements. This model was recommended by Brinkgreve et al. (2013) to model stiff volumes in soil, bedrock layers or strong massive structures in the soil. The equivalent pile axial stiffness is given by

1. $E_{\mathrm{p}} A_{\mathrm{p}}=(E A)_{\mathrm{eq}}$ 
and the equivalent pile bending stiffness is

2. $\quad E_{\mathrm{p}} I_{\mathrm{p}}=(E I)_{\mathrm{eq}}$

where $E_{\mathrm{p}}$ is the Young's modulus of steel (205 GPa), $A_{\mathrm{p}}$ is the cross-sectional area of the tubular pile shaft and $I_{\mathrm{p}}$ is the moment of inertia of the tubular pile shaft.

Plate elements were assigned to the outside of the pile surface with a very low stiffness $\left(E I=0.002 \mathrm{kN} \cdot \mathrm{m}^{2}\right)$. These were included to allow later attachment of the helical plates. The helical plates were modelled using plate elements composed of six-node triangular elements. The deformation in the plate elements due to the applied load was based on Mindlin's plate theory (Bathe, 1996). The thickness of the plate used for the helical plates in the study was taken as $25 \mathrm{~mm}$ to limit deflection of the flanges and based upon successful field deployment experience reported by Sakr (2010a); in the validation cases this was chosen to match those used in each particular case.

The pile-soil interfaces were modelled using 12-node interface elements with a Mohr-Coulomb model compatible with the six-noded triangular sides of both the plate and soil elements. The interface elements had zero thickness as each node pair was identical and had the same coordinates (Brinkgreve et al., 2013). The interface elements were assigned to the screw pile shaft, the screw pile tip and across the surface of the helical plates to model a pile-soil interface with $\tan \delta^{\prime} / \tan \phi^{\prime} \approx 0 \cdot 7$ based on the direct shear box interface tests results for mild steel sheared against silica sand reported by Lauder et al. (2013).

\subsubsection{Soil constitutive model}

The soil in this study was modelled using the 'hardening soil with small strain stiffness' (HS small) constitutive model (Schanz et al., 1999) with ten-node tetrahedral elements based upon recent verification and calibration work undertaken at the University of Dundee. This elasto-plastic model is able to capture the increase of stiffness with effective confining stress and degradation with increasing strain, along with increased stiffness during unloading-reloading as compared with virgin loading. This non-linear elastic behaviour is coupled with a hardening plasticity model in which the yield surface evolves (hardens) with volumetric and deviatoric strain. It does not capture post-peak softening at large strains, but has been shown to provide good matches to field test load-displacement data over the working load range in sands for both bored piles (Tolooiyan and Gavin, 2013) and continuous helical displacement (CHD) piles - a type of cast in situ concrete screw pile (Knappett et al., 2016).

The parameters for this constitutive model were selected to represent a specific test sand (Congleton HST95) used in previous and ongoing physical model tests of screw piles in sand as determined through element testing by Al-Defae et al. (2013); these parameters are summarised in Table 1. This model has been used in several previous studies where FEA was validated against $1 \boldsymbol{g}$ and centrifuge physical model testing (e.g. Al-Baghdadi et al., 2016; Aldaikh et al., 2014; Al-Defae et al., 2013; Knappett et al., 2014, 2015, 2016).

\subsection{Mesh details}

The mesh was generated based upon the very fine element distribution option with local refinement for the pile geometry (local element refinement factor $=0 \cdot 125$ ) to reduce the element size gradually near the screw pile geometry and to obtain accurate results. In order to control this process, the mesh was divided into different zones to allow localised mesh refinement close to the pile and limit the total number of elements in the analysis (Figure 2). To reduce the element size around the pile, a zone with plan dimensions of $13 D_{\mathrm{p}} \times 13 D_{\mathrm{p}}$, which extended to $2 D_{\mathrm{h}}$ below the pile base, was used to refine the mesh near the pile. Initial trials were performed on several mesh refinement schemes in order to determine the optimum mesh refinement (Figure 3$)$ for both a screw pile $\left(D_{\mathrm{p}}=0.75 \mathrm{~m}\right.$, $\left.D_{\mathrm{h}}=2.0 \mathrm{~m}, S / D_{\mathrm{h}}=1.75\right)$ example and a $\operatorname{SSP}\left(D_{\mathrm{p}}=0.75 \mathrm{~m}\right)$ for comparative lateral displacements $\left(0 \cdot 1 D_{\mathrm{p}}\right)$. Figure 3 clearly shows that no significant benefit was achieved in either case by

Table 1. Soil and pile material parameters for the FEA

\begin{tabular}{|c|c|}
\hline Soil parameter & HST95 (Al-Defae et al., 2013) \\
\hline Drainage type & Drained \\
\hline Oedometer stiffness, $E_{\text {oed }}^{\text {ref }}: \mathrm{kPa}$ (at $\left.p^{\prime}=100 \mathrm{kPa}\right)$ & $25 D_{r}+20 \cdot 22\left(\times 10^{3}\right)$ \\
\hline Secant stiffness, $E_{550}^{\text {ref: }} \mathrm{kPa}\left(\right.$ at $p^{\prime}=100 \mathrm{kPa}$ ) & $1.25 E_{\text {ref }}^{\text {ref }}$ \\
\hline Unload/reload stiffness, $E_{\mathrm{ur}}^{\text {ref: }} \mathrm{kPa}$ (at $p^{\prime}=100 \mathrm{kPa}$ ) & $3 E_{\text {oed }}^{\text {ref }}$ \\
\hline Friction angle, $\phi^{\prime}$ : degrees & $20 D_{r}+29$ \\
\hline Effective cohesion intercept, $\mathrm{C}_{\mathrm{ref}}^{\prime} \mathrm{kPa}$ & 0 \\
\hline Angle of dilation, $\Psi$ : degrees & $25 D_{r}-4$ \\
\hline Unload-reload Poisson's ratio, $v_{\text {ur }}$ & $0 \cdot 2$ \\
\hline Shear modulus at very small strains, $\mathrm{G}_{0}^{\text {ref: }} \mathrm{kPa}$ & $50 D_{r}+88 \cdot 8\left(\times 10^{3}\right)$ \\
\hline Reference shear strain (at $G_{s}=0.722 G_{0}$ ), $\gamma_{0.7}$ & $1.7 D_{r}+0.67\left(\times 10^{-4}\right)$ \\
\hline Power of stress level dependency of stiffness, $m$ & $0 \cdot 6-0 \cdot 1 D_{\mathrm{r}}$ \\
\hline Total unit weight, $\gamma_{\text {total }}: \mathrm{kN} / \mathrm{m}^{3}$ & $3 D_{r}+14 \cdot 5$ \\
\hline
\end{tabular}




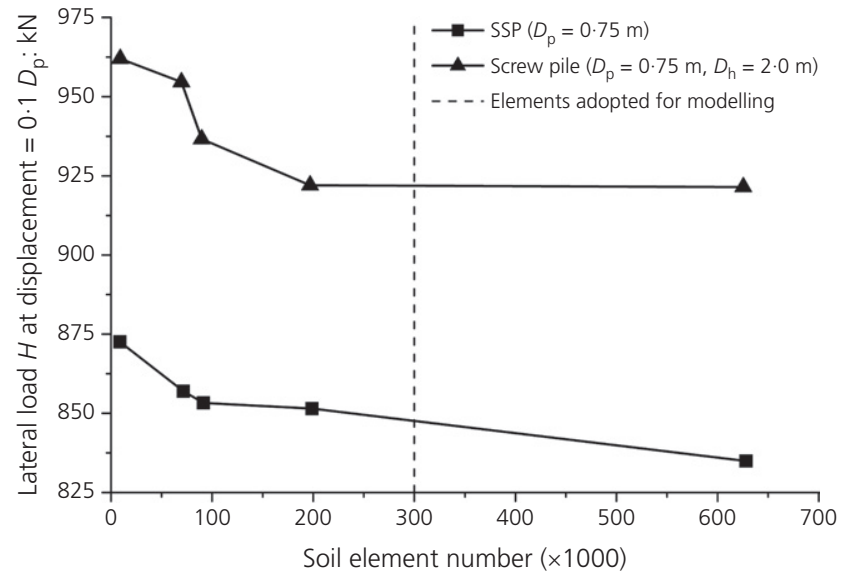

Figure 3. Mesh sensitivity analysis comparison for a SSP and a screw pile with a $2 \mathrm{~m}$ helical plate diameter at $1.5 \mathrm{~m}$ depth considered under pure lateral loads

greatly exceeding 200 elements and thus a refinement scheme with approximately 300 total elements was selected for the analysis.

\subsection{Numerical modelling analysis scheme}

Two types of pile loading regime were considered in this study. Firstly, individual simulations were undertaken of pile performance under purely axial or lateral loading to act as normalisation points (pure compressive capacity $=V_{\mathrm{c} \text {,ult }}$, pure tensile capacity $=V_{\mathrm{t} \text {,ult }}$ and pure horizontal capacity $=H_{\mathrm{o}}$ ) to study the effects of combined loading. The piles under purely axial and lateral loading were modelled in three stages. The in situ geostatic stresses were generated in the first stage for $K_{0}=1-\sin \phi^{\prime}$ conditions. In the second stage, the pile geometry was activated for this calculation phase so that the piles were wished-in-place. The load was applied in the third stage by means of a monotonically increasing point displacement (i.e. under displacement control) to reach pile failure. For piles subjected to pure axial loading (tension or compression) the ultimate vertical pile capacity $\left(V_{\mathrm{c} \text {,ult }}\right.$ or $\left.V_{\mathrm{t} \text {,ult }}\right)$ was based on pile head displacement equal to $10 \%$ of the equivalent pile core diameter $\left(D_{\mathrm{p}}=750 \mathrm{~mm}\right)$ (i.e. $\left.75 \mathrm{~mm}\right)$. The same process was undertaken for lateral loading to determine the ultimate lateral pile capacity $\left(H_{\mathrm{o}}\right)$ where the failure criterion was based on lateral pile head displacement $(y)$ that caused a pile tilt of $0 \cdot 25^{\circ}$ to the vertical at the mudline. This has its origins in the criteria used for wind turbine foundations where the permanent accumulated monopile head tilt $(\theta)$ that can be supported by an offshore wind turbine is limited to $0.25^{\circ}$ at the seabed (DNV, 2014; Rosbjerg and Gravesen, 2009).

Installation effects were not considered in the modelling and the piles were modelled as wished-in-place with an initial $K_{0}$ lateral earth pressure regime (Jaky, 1944). This is effectively making the assumption that the screw pile installation has no effect on the adopted soil properties. This assumption has previously been suggested for ribbed piles loaded in compression by Knappett et al. (2014) as the failure surface between the surrounding soil and the screw pile is defined by the helical plate diameter $\left(D_{\mathrm{h}}\right)$ where the soil is likely to be less disturbed, so long as the helical plate spacing is sufficiently close to induce soil-soil shear between the tips of the helical plates. Some additional validation studies (reported in the next section) were also conducted against previous onshore field pile load test data to confirm the validity of this approach prior to the parametric study.

The piles subjected to combined loading regimes were modelled in four implementation stages. The first and second stages were as for the unidirectional cases just described. In the third stage, only the axial load was applied by means of a point load as a percentage of the ultimate vertical screw pile capacity (from $0 \cdot 2 V_{\text {ult }}$ to $0 \cdot 8 V_{\text {ult }}$ ) determined based on $0 \cdot 1 D_{\mathrm{p}}$ displacement. The vertical displacements due to the axial load were recorded but they were not used in the final results as they were significantly less than $0 \cdot 1 D_{\mathrm{p}}$ for all cases (based on the magnitude of the axial load). In the final stage, the vertical load was held constant and the lateral load was applied under displacement control. This approach was adopted by previous researchers (Karthigeyan, 2008; Karthigeyan et al., 2007; Zadeh and Kalantari, 2011) to study SSP performance under combined vertical and lateral loading. Also, this approach is similar to pile loading offshore, as vertical loads from the offshore wind structure are applied first on installation of the turbine (normally under calm sea conditions so that $H \approx 0$ ) followed by lateral loading under the action of wind and waves during operation of the wind turbine.

\section{Validation of numerical modelling}

The numerical modelling assumptions used within the 3D FEA were first validated against field case study results for screw piles under purely vertical tension, compression and lateral loading in sand (as reported by Sakr (2010a, 2010b) and Zhang (1999)). Field test results for combined loading were not available in the literature. The parameters required for the HS small constitutive model were obtained based upon the available soil parameters for each case study. Where specific parameters were not available they were generated based upon the case study in situ relative density (either reported or determined from standard/cone penetration testing (SPT/CPT) data) using the correlations in Table 1 (Al-Defae et al., 2013). These correlations have previously been successfully used for simulating the results of field pile load tests of CHD piles, as reported by Knappett et al. (2016).

\subsection{Case study 1: Northern Alberta, Canada}

Sakr (2010a, 2010b) reported the response of screw piles from field trials where the piles were installed in medium dense to very dense sands in northern Alberta, Canada. Three different test piles from this case study were used for validation (ST1P4, 
Table 2. Screw pile configurations for verification of results of Sakr (2010a, 2010b) and Zhang (1999)

\begin{tabular}{|c|c|c|c|c|c|c|c|c|}
\hline \multirow[b]{2}{*}{ Test } & \multirow[b]{2}{*}{ Load type } & \multicolumn{2}{|c|}{ Shaft } & \multicolumn{2}{|c|}{ Helical plate } & \multirow{2}{*}{$\begin{array}{l}\text { Number of } \\
\text { helical plates }\end{array}$} & \multirow{2}{*}{$\begin{array}{c}\text { Embedment } \\
\text { depth: } m\end{array}$} & \multirow{2}{*}{$\begin{array}{l}\text { Helical plate } \\
\text { spacing ratio: } S / D_{\mathrm{h}}\end{array}$} \\
\hline & & $D_{\mathrm{p}}: \mathrm{mm}$ & $t_{\mathrm{p}}: \mathrm{mm}$ & $D_{\mathrm{h}}: \mathrm{mm}$ & $t_{\mathrm{h}}: \mathrm{mm}$ & & & \\
\hline ST1P4 & Compression & 324 & $9 \cdot 5$ & 762 & $25 \cdot 4$ & 2 & $9 \cdot 0$ & 3 \\
\hline ST22P7 & Compression & 508 & $9 \cdot 5$ & 1016 & $25 \cdot 4$ & 1 & $5 \cdot 75$ & - \\
\hline ST17P3A & Lateral & 324 & $9 \cdot 5$ & 610 & $25 \cdot 4$ & 1 & $5 \cdot 6$ & - \\
\hline ST3P4 & Tension & 324 & $9 \cdot 5$ & 762 & $25 \cdot 4$ & 2 & $9 \cdot 5$ & 3 \\
\hline L322 & Lateral & 219 & $8 \cdot 18$ & 356 & $6 \cdot 71$ & 3 & $5 \cdot 18$ & 1.5 \\
\hline $\mathrm{TL}$ & Tension & 219 & 6.71 & 356 & $6 \cdot 71$ & 3 & $5 \cdot 18$ & 1.5 \\
\hline
\end{tabular}

Table 3. Soil parameters for verification of results of Sakr (2010a, 2010b)

\begin{tabular}{lclccc} 
Soil layer & Depth: $\mathbf{m}$ & Soil description & $\begin{array}{c}\text { SPT blow count } \\
\text { per } \mathbf{3 0 0} \mathbf{~ m m}\end{array}$ & $\begin{array}{c}\text { Total unit weight, } \\
\boldsymbol{\gamma}: \mathbf{k N} / \mathbf{m}^{\mathbf{3}}\end{array}$ & $\begin{array}{c}\text { Friction angle, } \\
\boldsymbol{\phi}^{\prime}: \text { degrees }\end{array}$ \\
\hline 1 & $0-11 \cdot 4$ & Sand, medium dense to very dense & $14-58$ & 18 & 35 \\
2 & $11.4-33$ & Sand, dense to very dense & $45-92$ & 20 & 40
\end{tabular}

ST3P4 and ST17P3A), more details of which may be found in Table 2. The screw piles were installed to depths $(L)$ ranging from 5.6 to $9.5 \mathrm{~m}$, had a pile shaft or core diameter $\left(D_{\mathrm{p}}\right)$ of $0.324 \mathrm{~m}$ and a screw plate diameter $\left(D_{\mathrm{h}}\right)$ ranging from 0.61 to $0.762 \mathrm{~m}$. The wall thickness of the core $\left(t_{\mathrm{p}}\right)$ was $9.5 \mathrm{~mm}$ with helical plates $25.4 \mathrm{~mm}$ thick $\left(t_{\mathrm{h}}\right)$ for all piles tested. The soil at the site was divided into two sub-layers for modelling, based on the limited available ground investigation data. These consisted of a sand layer (medium dense to very dense) down to $11.4 \mathrm{~m}$ depth with phreatic level at $3.6 \mathrm{~m}$ below ground level and a dense to very dense sand layer down to more than $23 \mathrm{~m}$ below the screw pile tip. A summary of the soil properties reported by Sakr (2010b) is shown in Table 3. The relative density used for parameter selection was determined from the average results of SPT testing (Table 2) based on the procedure outlined by Skempton (1986). The resulting average relative densities $\left(D_{\mathrm{r}}\right)$ over the pile length for layer 1 and 2 were $79 \%$ and $82 \%$ respectively. The load was applied at the pile head in each case by means of displacement control and with the maximum displacement set to match that for the field tests. Fully drained conditions were used for all of the calculations and the pile was wished-in-place as discussed previously.

\subsection{Case study 2: Sand pit site, Alberta, Canada}

The second case study chosen for verification followed the field work of Zhang (1999), which consisted of a testing programme of eight full-scale screw piles installed in cohesionless soil at a sand pit site in Alberta, Canada, including compression, tension and lateral loading tests. The soil at the sand pit site was described as sand dunes with medium- to finegrained sand with silt. A summary of the soil properties as reported by Zhang (1999) is shown in Table 4. The pile geometries used in the field tests selected for validation were a core diameter of $219 \mathrm{~mm}$, with three helical plates $(356 \mathrm{~mm}$ diameter) at spacings of $533 \mathrm{~mm}\left(S / D_{\mathrm{h}}=1 \cdot 5\right)$; the embedded length
Table 4. Soil parameters for verification of Zhang (1999)

\begin{tabular}{|c|c|c|c|c|c|}
\hline $\begin{array}{l}\text { Soil } \\
\text { layer }\end{array}$ & $\begin{array}{c}\text { Depth: } \\
\text { m }\end{array}$ & $\begin{array}{c}\text { Relative } \\
\text { density, } \\
D_{\mathrm{r}}: \%\end{array}$ & SPT $N$ & $\begin{array}{c}\text { Total unit } \\
\text { weight, } \gamma \text { : } \\
\mathrm{kN} / \mathrm{m}^{3}\end{array}$ & $\begin{array}{l}\text { Friction } \\
\text { angle, } \phi^{\prime} \text { : } \\
\text { degrees }\end{array}$ \\
\hline 1 & 0.762 & $37 \cdot 7$ & $14-58$ & $17 \cdot 3$ & 33 \\
\hline 2 & 1.524 & $43 \cdot 2$ & $45-92$ & $17 \cdot 8$ & 35 \\
\hline 3 & $2 \cdot 286$ & 37.5 & $14-58$ & $17 \cdot 3$ & 33 \\
\hline 4 & 3.048 & 34.5 & $45-92$ & 17 & 32 \\
\hline 5 & 4.572 & 18 & $14-58$ & 16 & 30 \\
\hline 6 & $5 \cdot 334$ & 15 & $45-92$ & 14 & 30 \\
\hline
\end{tabular}

was $5 \cdot 18 \mathrm{~m}$. Numerical analysis was performed following the approach described in Section 3.1.

\subsection{Results of validation}

A comparison of the field test results of the axial compressive load-displacement behaviour with predicted data (Figure 4) reveals that the 3D FEA with simplifications with respect to modelling of the installation is very good at predicting the load-displacement response behaviour when a screw pile is subjected to compression loading, at least for the case studies examined here. This is in agreement with the suggestions of Knappett et al. (2014) that installation effects may not require a modification to the in situ parameters where soil-soil shear is occurring at the periphery of the helical plates (where $S / D_{\mathrm{h}}$ is optimised) during axial compressive loading and where the pile tip and lower plate are installed in relatively undisturbed soil (Gavin et al., 2014).

Figure 5 shows the results of simulations of pure lateral loading and, again, the predictions of behaviour are good with less than $7 \%$ overprediction of lateral capacity (this is thought to be a result of the simplification of the relative density distribution used for simulation). The overprediction may also be due to 


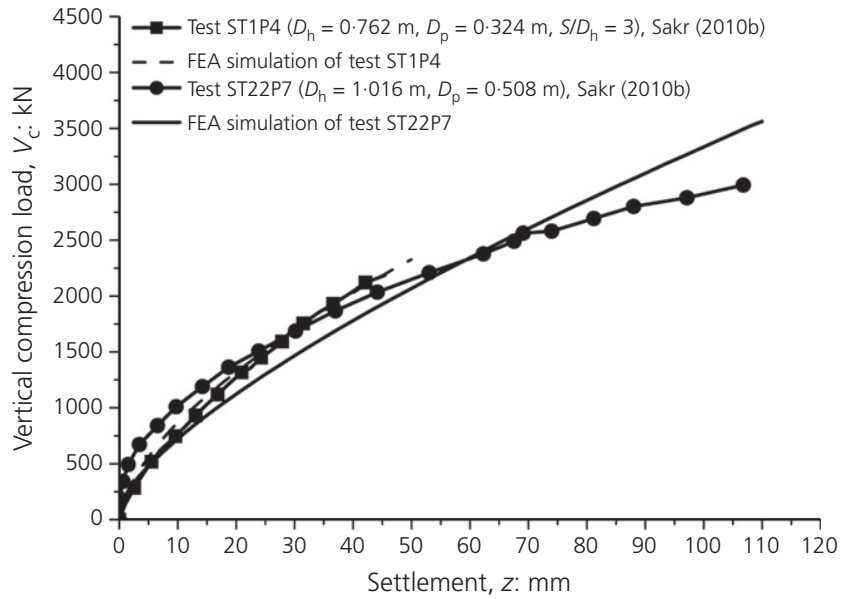

Figure 4. FEA predicted screw pile load-displacement behaviour under compressive axial loading verified for the field datasets from Sakr (2010b) for tests ST1P4 and ST22P7

disturbance of the near-surface soil during screw pile installation in reality, to a diameter equivalent to the pile plates, whereas the modelling assumes no installation effects. However, any reduction in soil density due to installation would be offset by installation of the screw pile, which would increase the radial effective stress regime close to the pile (Jeffrey et al., 2016). The aim of the validation was only to prove that $3 \mathrm{D}$ FEA has the ability to capture screw pile behaviour representatively, and thus further improvement was not pursued here.

Results of the modelling of uplift or tensile pull-out (Figure 6) show that, in the case of the Sakr (2010b) results, the FE model appears to overpredict the initial stiffness during pullout and underpredict ultimate capacity whereas the opposite performance was observed for the data reported by Zhang (1999). This may be a result of the simplification of wished-inplace simulation as the upper helical plates in the field case may cause a reverse bearing capacity mechanism propagating up towards the surface, which may pass through soil disturbed by the installation process. Interestingly, though, Mosquera et al. (2015) undertook numerical modelling of a single plate screw pile subjected to tensile uplift and found that the upward shallow failure mechanism was defined by the zone of soil swept by the plate during installation, leading to a cylindrical failure mechanism shearing against undisturbed soil rather than the more normally assumed wider uplift type bearing capacity mechanism. This then limits the effect of disturbance of soil above the plate and is more consistent with the multiple flange cylindrical mechanism that is induced by the optimised plate spacing used in the current study. Tsuha et al. (2012) also suggest that the soil above the upper plates is more disturbed than the soil above the lowest plate, even for an optimised plate spacing $\left(S / D_{\mathrm{h}}\right)$. This may contribute further to variations between field behaviour and numerical modelling, especially where the spacing of the plates has not been optimised or only

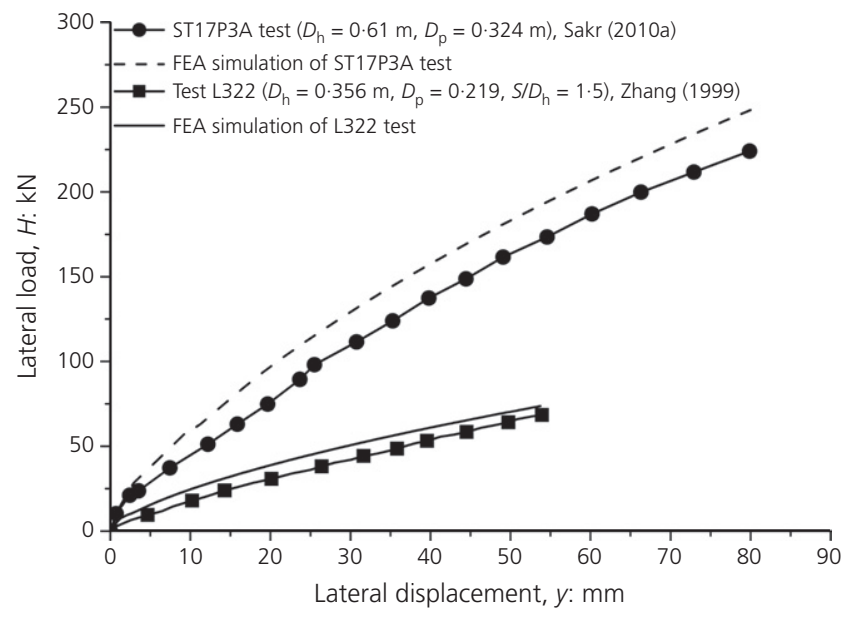

Figure 5. FEA predicted screw pile load-displacement behaviour under lateral loading verified for test ST17P3A (Sakr, 2010a) and test L322 (Zhang, 1999) field datasets

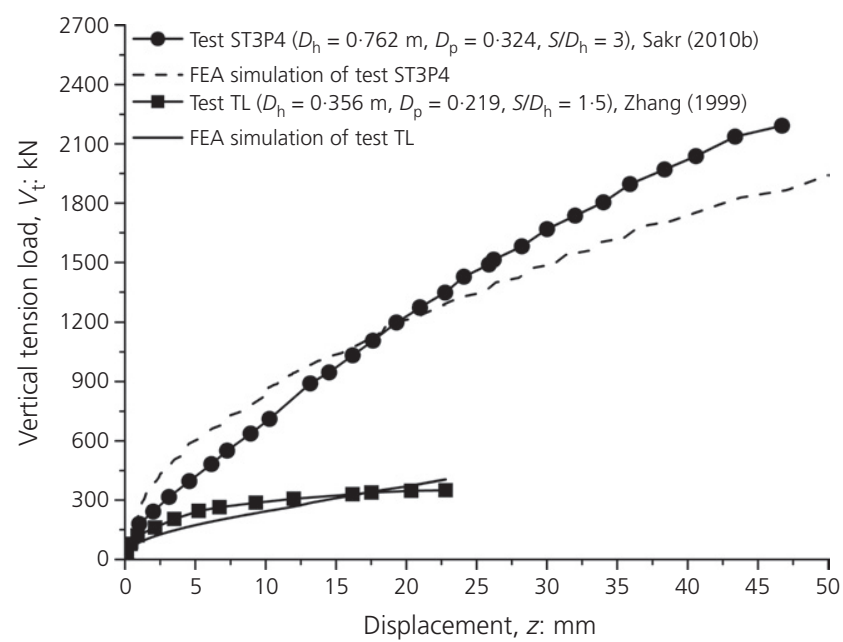

Figure 6. FEA predicted screw pile load-displacement behaviour under tensile axial loading verified for test ST3P4 (Sakr, 2010b) and test TL (Zhang, 1999) field datasets

a single plate is present. That said, the simulated loaddisplacement behaviour tends to cross the field pile behaviour at $0 \cdot 1 D_{\mathrm{p}}$ and $0 \cdot 15 D_{\mathrm{p}}$, which covers the range used for ultimate pile capacity comparison; this suggests that the FE prediction is still valuable for prediction of ultimate uplift capacity and the nature of the study undertaken in this paper.

\section{Results and discussion of the parametric study}

As well as investigating the effect of varying the magnitude of the vertical load on lateral performance, the pile length ( $L=5 \mathrm{~m}$ and $20 \mathrm{~m} ; L / D_{\mathrm{p}}=6.67$ and 26.67) and helical plate diameter $\left(D_{\mathrm{h}}=1.5,2.0\right.$ and $2.5 \mathrm{~m} ; D_{\mathrm{h}} / D_{\mathrm{p}}=2.0-3.33$, $\left.S / D_{\mathrm{h}}<2 \cdot 0\right)$ of the screw pile were also varied while the pile 
core diameter was kept constant $\left(D_{\mathrm{p}}=0.75 \mathrm{~m}\right)$ throughout the study. The top helical plate was placed at a depth of $1.5 \mathrm{~m}$ below the mudline and the pile tip was modelled as a flat closed (i.e. plugged) rigid element (Figure 1). The pile lengths were selected to represent both a short rigid pile $(5 \mathrm{~m})$ and a long flexible pile $(20 \mathrm{~m})$ in order to represent piles behaving as a rotating rigid body or bending under lateral load (Fleming et al., 2009). Prior to commencing the analysis, the effect of modelling the helical plates as flat plates was also checked and there was found to be less than $1 \%$ variation in lateral load capacity (irrespective of the direction of loading) and less than $5 \%$ variation in axial capacity for the $20 \mathrm{~m}$ long pile where the inclusion of pitch caused a slight increase in capacity.

\subsection{Vertical loading effects on the lateral capacity of straight shafted piles}

The lateral load-displacement response for the $5 \mathrm{~m}$ and $20 \mathrm{~m}$ long SSPs are first presented (Figure 7) to highlight the behaviour that may be observed for a standard pile geometry. It is clear from the results that vertical compressive loads enhance the horizontal capacity and stiffness of the pile, while tensile forces reduce the capacity and stiffness. A similar observation was made by $\mathrm{Mu}$ et al. (2015), based on in-flight experimental (centrifuge) tests conducted on SSPs loaded axially and laterally. There is a relatively small difference in the pure horizontal load capacity between the shorter and longer piles, suggesting that $L / D_{\mathrm{p}}=6.67$ is close to the transition from rigid rotation to bending down to a critical length (this transition or critical pile length occurs at $L / D_{\mathrm{p}}=9.5$ according to Fleming et al. (2009), for the configuration tested). What is particularly interesting to note is that the relative enhancement in lateral capacity for the $20 \mathrm{~m}$ long pile appears to be greatly reduced when compared with that in the $5 \mathrm{~m}$ long pile. This is a result of the uniform rotation of the rigid short pile whereas, due to fixity in the long pile, the relative rotation reduces with depth, suggesting less mobilisation of lateral resistance for the long pile. The short pile is also likely to see much greater enhancement through the passive resistance of the bottom helical plate, which will generate a bearing capacity type mechanism during rotation.

In order to further understand the effect of combined loading and allow a comparison with screw piles, the results of the FEA were interrogated in greater detail: Figure 8(a) shows the lateral or radial effective stresses $\left(\sigma_{\mathrm{r}}^{\prime}\right)$ in the soil close to the $20 \mathrm{~m}$ long SSP (over the upper section only). The points chosen to measure the effective soil stresses were typically $0 \cdot 04 D_{\mathrm{p}}$ from the pile shaft. As the vertical load on the pile increases the radial stress experienced by the soil during lateral loading is increased (i.e. the soil has increased shear resistance). This is explained in Figure 8(b) through consideration of the mobilised passive earth pressure coefficient ratio $K / K_{\mathrm{p}}$ (where $K=\sigma_{\mathrm{r}}^{\prime} / \sigma_{\mathrm{v}}^{\prime}$ and $K_{\mathrm{p}}=1+\sin \phi^{\prime} / 1-\sin \phi^{\prime}$ with $K_{\mathrm{p}}$ taken as 5.83 in this case), which suggests that lateral loading combined with vertical loading mobilises $30-68 \%$ of the potential

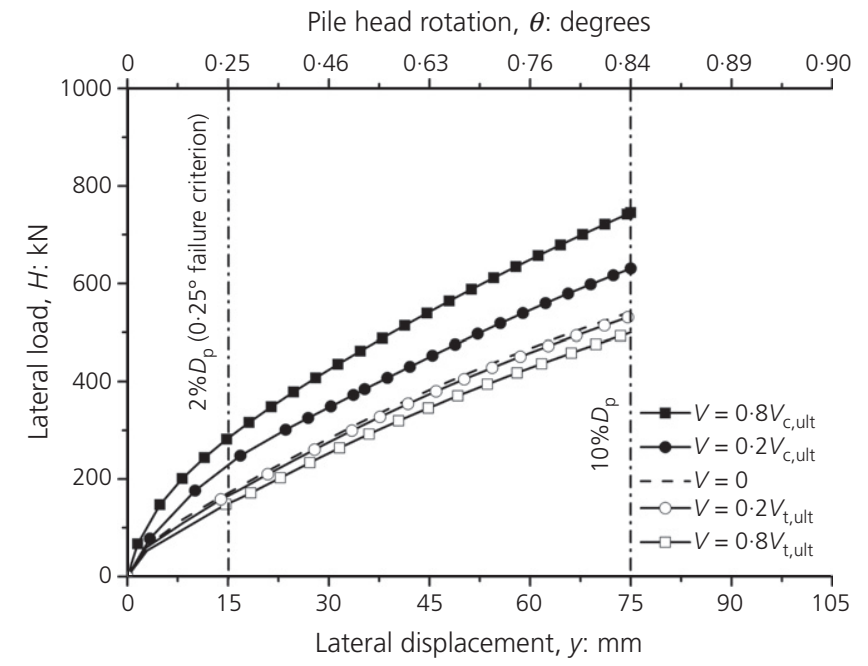

(a)

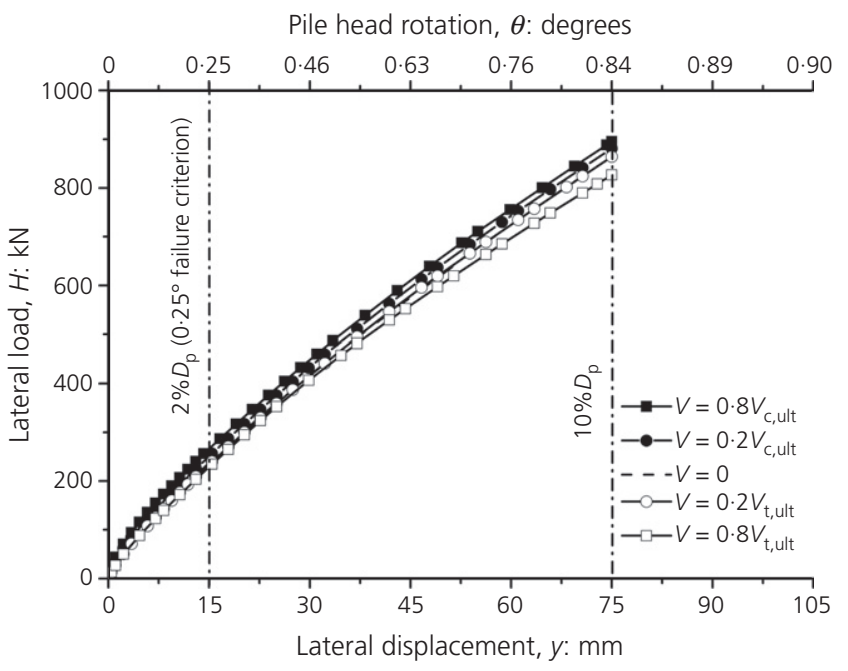

(b)

Figure 7. Effect of increasing axial compressive and tensile loads on lateral pile load-displacement behaviour in saturated dense sand $\left(D_{\mathrm{r}}=80 \%\right)$ for (a) a $5 \mathrm{~m}$ long $\operatorname{SSP}\left(D_{\mathrm{p}}=750 \mathrm{~mm}\right)$ and (b) a $20 \mathrm{~m}$ long $\operatorname{SSP}\left(D_{\mathrm{p}}=750 \mathrm{~mm}\right)$

passive resistance. This ratio reduces with increasing vertical compressive loading and thus the increase in vertical load induces greater vertical effective stress within the soil surrounding the pile as the vertical load is transferred from pile to soil. In contrast, during the application of tensile loads, the radial stress tends to reduce slightly below that for the zero tensile load case (Figure 8(a)) and the mobilised passive earth pressure is increased, suggesting that vertical stress is reduced (Figure 8(b)). It can be seen from Figure 8(a) that the radial effective stress drops to a minimum at approximately $6.1 \mathrm{~m}$ $\left(L / D_{\mathrm{p}}=8 \cdot 1\right.$, which is similar to that predicted by Fleming et al. (2009)). This supports the suggestion of limiting rotation in the long-pile case and explains the difference in enhancement observed between the short and long piles. 
Geotechnical Engineering

Volume 170 Issue GE3
Effects of vertical loading on lateral screw

pile performance

Al-Baghdadi, Brown, Knappett and Al-Defae

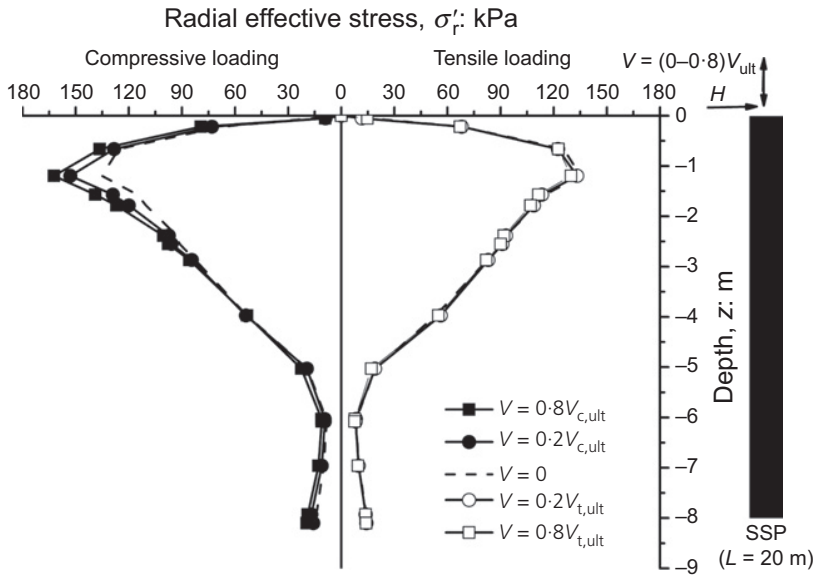

(a)

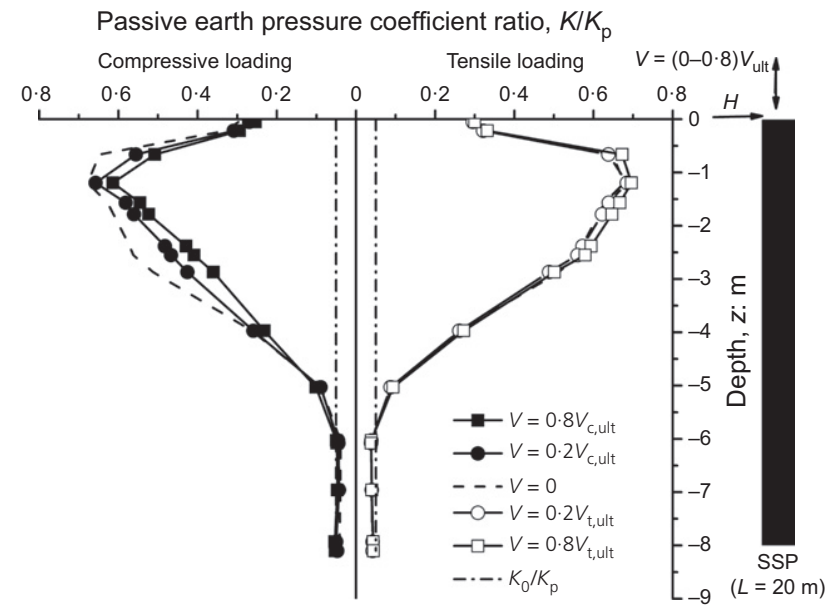

(b)

Figure 8. Variation of (a) radial effective stress and (b) passive earth pressure coefficient ratio with depth for the $20 \mathrm{~m}$ long SSP under combined axial (shown for compression and tension) and lateral loading

\subsection{Vertical loading effects on the lateral capacity of screw piles}

Figure 9 shows the effect of axial compression and tension loading on the lateral capacity of $5 \mathrm{~m}$ and $20 \mathrm{~m}$ long screw piles with $2.5 \mathrm{~m}$ diameter helical plates. It is clear that the inclusion of helical plates increases the lateral resistance of the pile but, unless a vertical compressive load is applied, this enhancement is limited in nature ( $\sim 20 \%$ increase), as previously confirmed by Al-Baghdadi et al. (2015). However, what is apparent is that when the inclusion of helical plates is combined with vertical compressive loads the enhancement has the potential to increase. This behaviour is summarised in Figure 10 for both the pile lengths with different helical plate diameters shown for comparison (at $0.02 D_{\mathrm{p}}$ ). It is clear from Figure 10 that there is a relatively linear increase in lateral pile resistance with increasing normalised vertical load without any additional effect from the helical plate diameter that is not

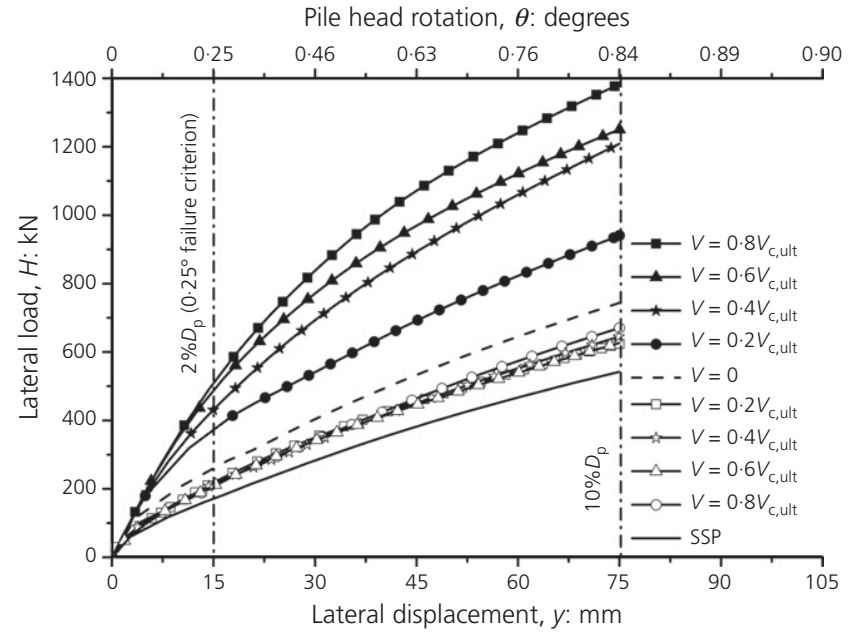

(a)

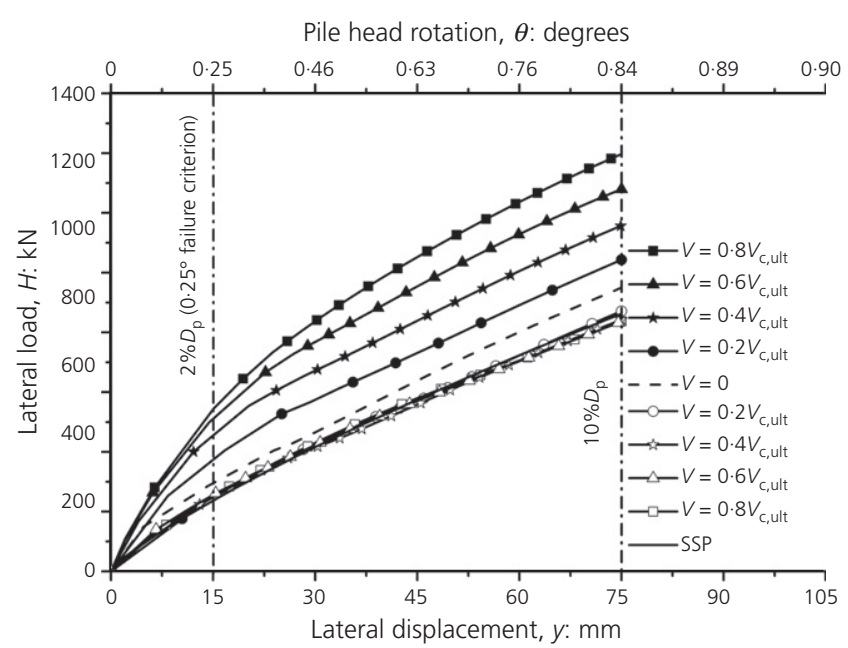

(b)

Figure 9. Effect of increasing axial compressive and tensile loads on lateral pile load-displacement behaviour for (a) a $5 \mathrm{~m}$ long screw pile $\left(D_{\mathrm{p}}=0.75 \mathrm{~m}, D_{\mathrm{h}}=2.5 \mathrm{~m}\right)$ and (b) a $20 \mathrm{~m}$ long screw pile $\left(D_{\mathrm{p}}=0.75 \mathrm{~m}, D_{\mathrm{h}}=2.5 \mathrm{~m}\right)$

already captured in the determination of $V_{\text {ult }}$ and $H_{\mathrm{o}}$ in vertical compression. Again, the effect of short- and long-pile behaviour (rotation) is seen to be significant when comparing to the SSP where, for the straight shafted $20 \mathrm{~m}$ long pile, there is little increase in horizontal capacity for $V / V_{\text {ult }}>0 \cdot 2$.

Figures 11 and 12 show the lateral effective stress distribution around the screw pile under combined loading, for the long and short screw piles respectively. The lateral stresses above the upper helical plate at low compressive loads in Figures 11 and 12 are of similar magnitude to those found for the SSP (Figure 8(a)), although there is a sharp drop to very low stresses just above the upper helical plate. The lateral stresses in the ground then increase significantly just below the upper helical plate but within another $0 \cdot 5-1 \mathrm{~m}$ depth this increase 


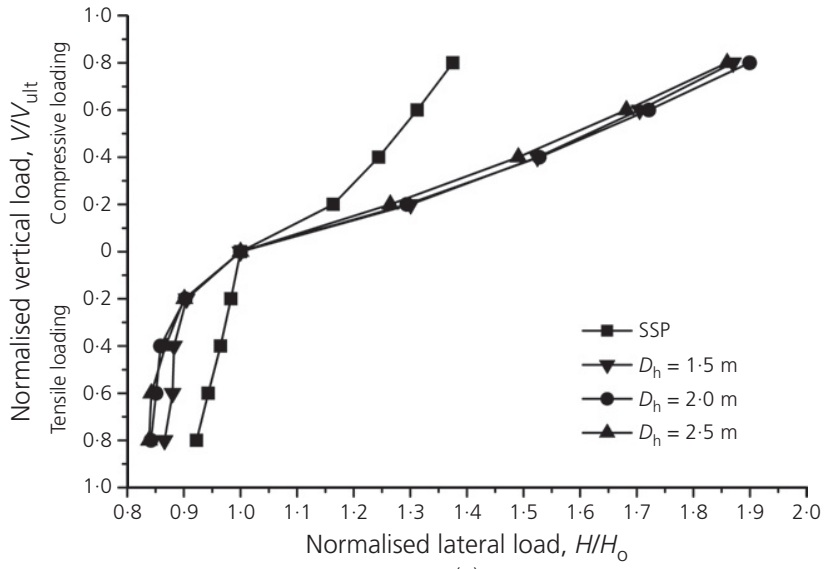

(a)

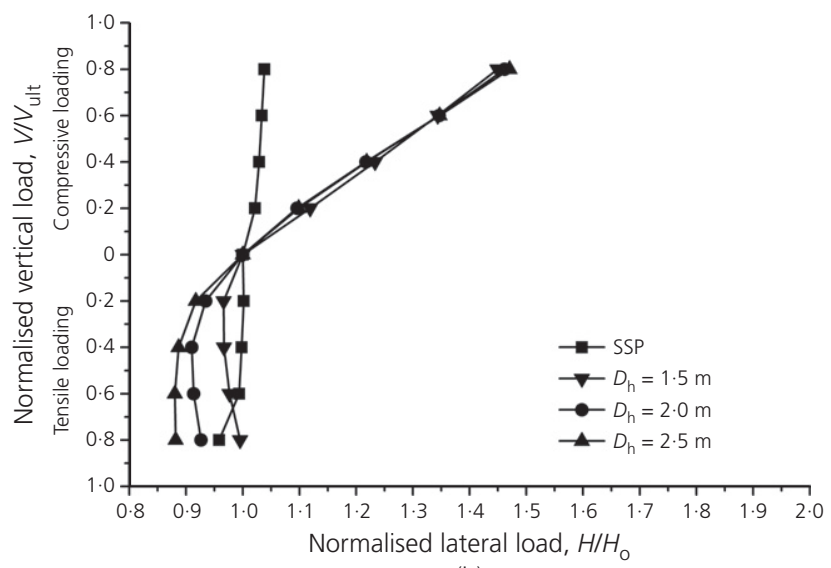

(b)

Figure 10. Comparison of normalised lateral pile resistance for both SSPs and screw piles: (a) $5 \mathrm{~m}$ long piles; (b) $20 \mathrm{~m}$ long piles

has again dropped to stresses associated with the SSP. The radial stress then drops to very low magnitude on approaching helical plate 2. For the short pile, the radial stresses again increase below the helical plate to a magnitude greater than helical plate 1 (Figure 11(a)) whereas, for the long pile, the peak radial stress below each helical plate reduces when going from helical plate 1 to helical plate 3 (at $8 \mathrm{~m}$ depth or $\left.10 \cdot 7 L / D_{\mathrm{p}}\right)$, which is below the critical depth. The radial stresses then increase with depth due the increases in vertical effective stress rather than lateral loading as the depth is below the critical depth. It is interesting to note that, although the peak radial stresses are at their maximum just below the helical plates in compression, this is associated with the lowest lateral earth pressure coefficients (Figure 11(b)) and tends to $K_{0}$ as the vertical stresses are at their maximum. By comparison, in tension, $K / K_{\mathrm{p}}$ is similar to that above the helical plate due to low vertical stresses below the helical plate.

Figures 12(a) and 12(b) clearly show the progressive mobilisation of radial stresses down the screw pile and opposing behaviour is seen in compression and tension. In contrast, very

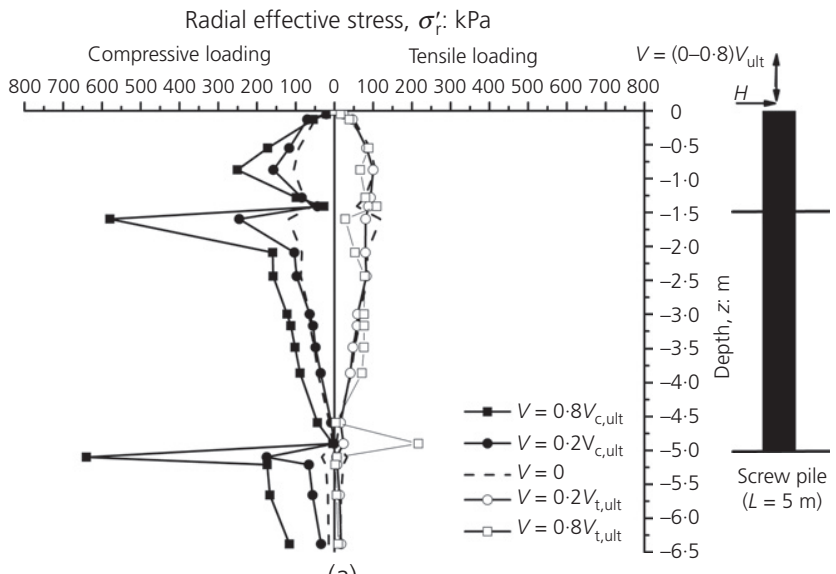

(a)

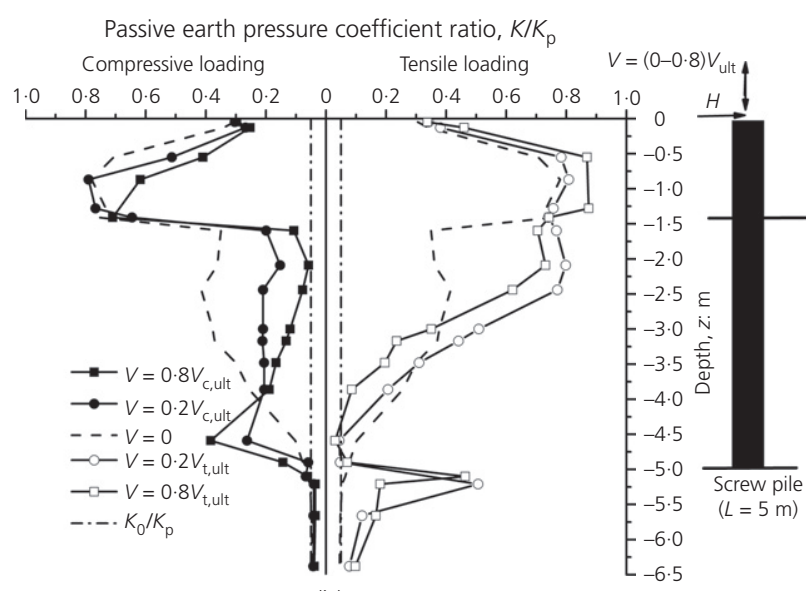

(b)

Figure 11. Variation of (a) radial effective stress and (b) passive earth pressure coefficient with depth for the $5 \mathrm{~m}$ long screw pile under combined axial (shown for compression and tension) and lateral loading $\left(D_{\mathrm{h}}=2.5 \mathrm{~m}\right)$

different behaviour is obtained for the lateral screw pile resistance when subject to tension with a reduction in normalised lateral capacity with the reduction becoming greater with increasing helical plate diameter, as shown in Figure 10(b). It is interesting to note that, as the tensile load increases further, there is some recovery of lateral capacity in tension for the longer pile; this can be explained by the increasing radial stress with depth seen in Figure 12(a) induced by the upward movement of the pile. It is also interesting to note the general behaviour of radial effective stress with increasing depth (below the critical depth) where the mobilisation of radial stress between each individual helical plate set is similar to that that seen down a SSP under purely axial loading.

These results suggest that the inclusion of helical plates on a screw pile under combined $V-H$ loading enhances the lateral pile resistance when subject to vertical compression loads, as compared with a SSP under combined loading. From a design perspective, this suggests that for screw piles of the geometry 


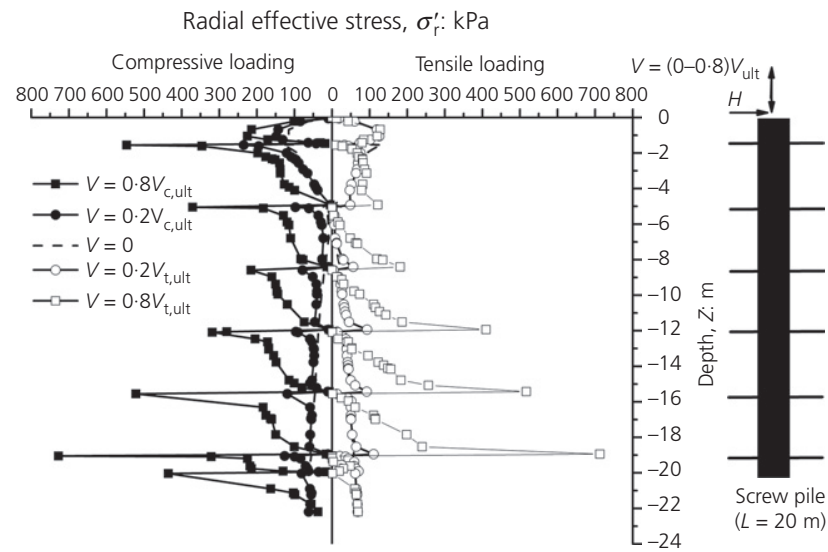

(a)

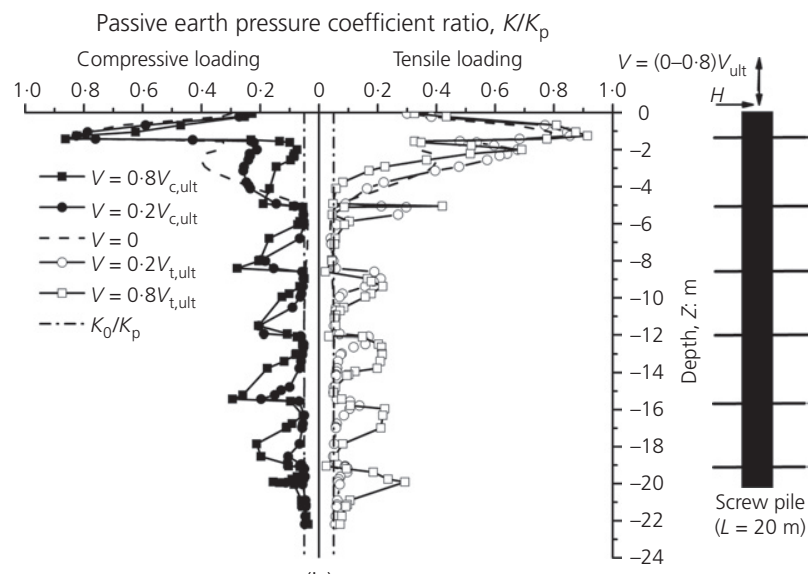

(b)

Figure 12. Variation of (a) radial effective stress and (b) passive earth pressure coefficient with depth for the $20 \mathrm{~m}$ long screw pile under combined axial (shown for compression and tension) and lateral loading $\left(D_{\mathrm{h}}=2.5 \mathrm{~m}\right)$

investigated here, for optimum performance under lateral loads they should be designed such that they are maintained in compression during operation; in other words, they lend themselves to being part of a piled jacket foundation system where the self-weight of the turbine and jacket substructure above the screw piles may be larger than the induced change in axial forces induced by resisting the overall moment applied to the foundation. Although the screw piles show enhancement up to $0 \cdot 8 V_{\mathrm{c} \text {,ult }}$, it is unlikely that they would be operated at such a low factor of safety (FoS) relative to their ultimate vertical capacity, with $0 \cdot 2 V_{\mathrm{c}}$ to $0 \cdot 4 V_{\mathrm{c}}$ being a more realistic operating condition (FoS of 2.5-5.0). However, even at these levels, the screw piles show enhanced lateral performance compared to a SSP (1.2 to 1.5 times the SSP resistance), as shown in Figures 10(a) and 10(b).

\subsection{Consideration of bending moments}

The results of the lateral investigation with increasing vertical loads highlight the enhanced capacity that can be gained from

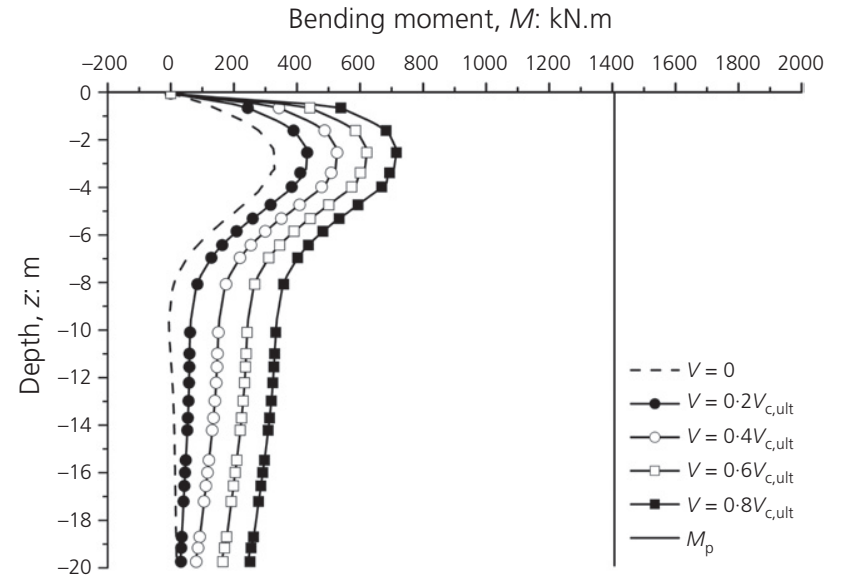

(a)

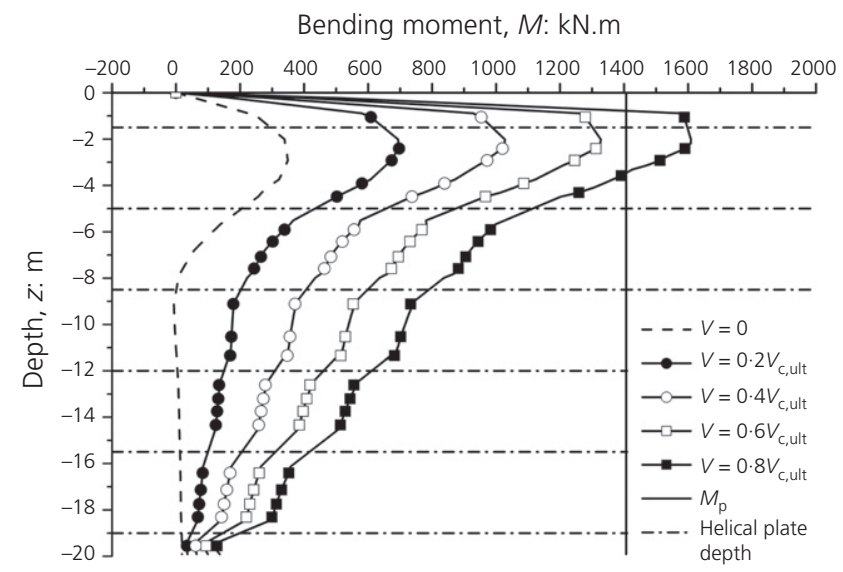

(b)

Figure 13. Variation of bending moment with depth for a $20 \mathrm{~m}$ long (a) SSP and (b) screw pile $\left(D_{\mathrm{h}}=2.5 \mathrm{~m}\right)$ under axial compression and lateral loading (pile shaft thickness $t_{p}=10 \mathrm{~mm}$ )

screw piles (Figure 9) and give insights into the mechanisms of how this enhancement occurs (Figures 11 and 12). The nature of this enhancement (Figures 11 and 12) highlights the fact that the helical plates of the screw pile are doing significant work, resulting in potentially increased bending moments in the helical plate pile connections and within the pile core itself. Figure 13 shows the bending moments induced in the core of a $20 \mathrm{~m}$ long SSP, with the plastic moment capacity indicated $\left(M_{\mathrm{p}}\right)$. It is clear that there is significant capacity of the core of the pile in this case $\left(D_{\mathrm{p}}=750 \mathrm{~mm}, t_{\mathrm{p}}=10 \mathrm{~mm}\right.$ and steel yield strength of $250 \mathrm{MPa}$ ). By comparison, for the $20 \mathrm{~m}$ long screw pile, the moment capacity of the pile core is exceeded between $0.6 V_{\mathrm{c}}$ and $0.8 V_{\mathrm{c}}$ (Figure 13(b)). This could be remedied in practice by utilising a thicker steel tube.

Figure 14 shows that the pile core wall thickness needs to be at least $14 \mathrm{~mm}$ for the moment capacity to exceed the induced moments. This is in line with the recommendations of the American Petroleum Institute (API, 2000) where the minimum 
thickness for the shaft in order to avoid local buckling during installation by driving can be obtained from

3. $t_{\mathrm{p}}=6 \cdot 35+\frac{D_{\mathrm{p}}}{100}$

This would result in a pile with $t_{\mathrm{p}}=14 \mathrm{~mm}$ (rounding up to the nearest integer value), although a $25 \mathrm{~mm}$ pile core wall thickness would be required to obtain a FoS of 1.6 on moment capacity. Again, it needs to be considered if the pile will actually be operating at such high vertical loads; for instance, for the $0 \cdot 2 V_{\mathrm{c}}-0 \cdot 4 V_{\mathrm{c}}$ case, a $10 \mathrm{~mm}$ wall thickness would be adequate for the moments induced. However, the results highlight that increased lateral capacity may come at a cost in terms of pile cross-section and that moment capacity may be a limiting factor that cannot be ignored when designing screw piles to generate significant lateral resistance. Additionally, the installation torque should be considered to avoid screw pile damage during installation (i.e. shaft buckling and screw plate separation from the central core). Scaling-up of the current onshore geometry will require significant torque for installation (not considered as part of this study). For example, Sakr (2010b) reported that torque up to $338 \cdot 3 \mathrm{kN}$.m was required to install a $0.5 \mathrm{~m}$ shaft diameter screw pile with a single screw plate at its base of $1 \mathrm{~m}$ diameter to a depth of $5.75 \mathrm{~m}$ in dense sand even after pre-drilling. This pile is of reduced dimensions to that considered in this study and suggests the potential for significant increase in torque requirements. Byrne and Houlsby (2015) suggest that the ratio $V_{\mathrm{t}, \text { ult }} D_{\mathrm{h}} / T$ may typically be of the order of 8 (where $T$ is the torque applied during installation). Thus, for a screw pile with a tensile capacity of $11 \mathrm{MN}$ (the largest pile simulated here), a torque of $3.4 \mathrm{MN}$.m would be required for installation. Based on the diameter of the pile core specified in this study, this magnitude of torque would require a pile wall thickness of $26 \mathrm{~mm}$ based upon a simple hand calculation of the torsional shear stress induced in a tube and without a FoS. This suggests that torque may be a more significant control on pile cross-section and may potentially limit the final length of pile installation.

\section{Conclusion}

A series of 3D FE numerical modelling simulations was carried out to investigate the influence of axial loads (tension and compression) on the lateral capacity of screw piles in sand. The numerical analyses and modelling approach for screw piles were firstly compared and validated with six field screw pile tests under compression, tension or lateral loads. The results show that an acceptable prediction of the screw pile capacity can be achieved for piles where the ratio of helical plate spacing to helical plate diameter $\left(S / D_{\mathrm{h}}\right)$ is less than three (such that soil-soil shearing is induced along the pile at the same diameter as the pile helical plates) and assuming a wished-in-place pile. However, it is acknowledged that installation effects may lead to reduced capacities in lateral and tensile loading that cannot be captured by this approach.

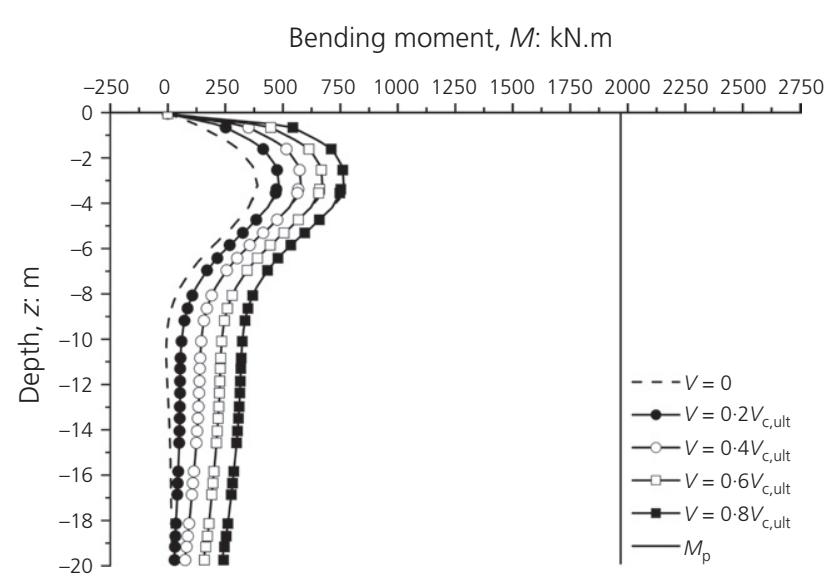

(a)

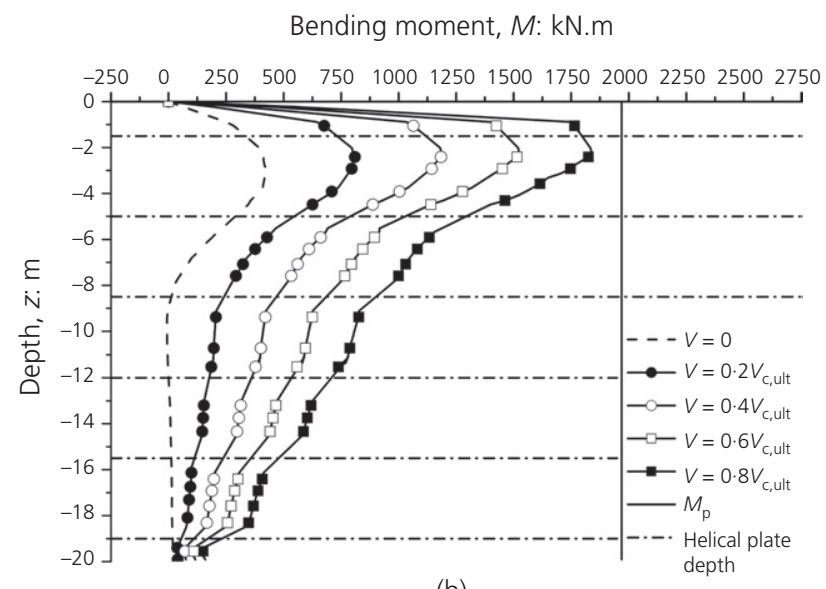

(b)

Figure 14. Variation of bending moment with depth for a $20 \mathrm{~m}$ long (a) SSP and (b) screw pile $\left(D_{\mathrm{h}}=2.5 \mathrm{~m}\right)$ under axial compression and lateral loading (pile shaft thickness $t_{p}=14 \mathrm{~mm}$ )

Subsequently, a range of axial load ratios (i.e. normalised by the ultimate axial capacity of a straight shafted pile (SSP)) was chosen to investigate how the screw pile lateral resistance varied under combined loading conditions when the axial loads were either in compression or tension. The main finding of these tests was that the axial load has a pronounced effect on the lateral capacity of both straight shafted and screw piles. In addition, the following conclusions can be drawn from this study.

(a) The lateral performance of both straight shafted and screw piles is enhanced under compressive vertical loading, with greater enhancement for screw piles. Both types of pile show much better performance when operated as short-mechanism piles rather than longmechanism piles, with the enhancement of long SSPs being minimal at loads above $0 \cdot 2 \mathrm{~V} / V_{\mathrm{ult}}$.

(b) For both pile types the lateral performance degraded under vertical tension loading (below a zero vertical load 
situation) irrespective of whether or not they were operating in short- or long-pile modes. However, the influence of the vertical tension load on the lateral capacity was more significant in short piles than in long piles.

(c) Interrogation of the radial stresses and earth pressures mobilised during modelling suggested that the presence of screw pile helical plates has the potential to increase the vertical compressive stresses below the helical plates and the resulting radial stresses, which in turn increases lateral pile resistance and vertical capacity of the pile core.

(d) Screw piles potentially offer good performance when used in jacket or tripod arrangements where the horizontal loading can be shared and where moments acting on the jacket can be carried principally in axial tension/compression, superimposed on the static selfweight. These will be particularly effective if the screw piles can remain (just) in compression under maximum environmental horizontal loads.

(e) The main drawback of the enhanced lateral capacity of screw piles with increasing vertical compressive loads is that greater bending moment is induced in the core of the pile. This implies a need to carefully consider the central core to ensure it has sufficient moment capacity so as not to yield under the combined effects of vertical and lateral loading.

\section{Acknowledgements}

The lead author would like to thank the Iraqi Ministry of Higher Education and Scientific Research (MOHESR) with collaboration and assistance from the Ministry of Municipalities and Public Works in Iraq (MMPW) for the financial support to undertake this work. Elements of this work were supported by EPSRC project EP/N006054/1: Supergen Windhub Grand Challenges Project: Screw piles for wind energy foundations. The authors would like also to thank David Husband for assistance and technical support with the numerical modelling software.

\section{REFERENCES}

Al-Baghdadi TA, Brown MJ, Knappett JA and Ishikura R (2015)

Modelling of laterally loaded screw piles with large helical plates in sand. In Proceedings of $3 r$ International Symposium on Frontiers in Offshore Geotechnics, Oslo, Norway (Meyer V (ed.)). Taylor \& Francis, London, UK, pp. 503-508.

Al-Baghdadi TA, Brown MJ and Knappett JA (2016) Development of an inflight centrifuge screw pile installation and loading system. In Proceedings of 3rd European Conference on Physical Modelling in Geotechnics (Eurofuge 2016), Nantes, France (Thorel L, Bretschneider A, Blanc M and Escofier S (eds)). IFSTARR, Nantes, France, pp. 239-244.

Aldaikh H, Knappett JA, Brown MJ and Patra S (2014) Evaluation of monotonic ultimate pull-out capacity of plate anchors in sand. In Advances in Soil Mechanics and Geotechnical Engineering, Volume 3: Information Technology in Geo-Engineering, Durham, UK (Toll D et al. (eds)). IOS Press, Amsterdam, the Netherlands, pp. 291-297.
Al-Defae AH, Caucis K and Knappett J (2013) Aftershocks and the whole-life seismic performance of granular slopes. Géotechnique 63(14): 1230-1244, http://dx.doi.org/10.1680/geot.12.P.149.

Anagnostopoulos C and Georgiadis M (1993) Interaction of axial and lateral pile responses. Journal of Geotechnical Engineering 119(4): 793-798.

API (American Petroleum Institute) (2000) Recommended Practice for Planning, Designing and Constructing Fixed Offshore PlatformsWorking Stress Design, RP 2A-WSD, 21st edn. American Petroleum Institute, Washington, DC, USA.

Bathe K (1996) Finite Element Procedures. Prentice Hall, Upper Saddle River, NJ, USA.

Bolton MD, Gui MW, Garnier J et al. (1999) Centrifuge cone penetration test in sand. Géotechnique 49(4): 543-552, http://dx.doi.org/10. 1680/geot.1999.49.4.543.

Brinkgreve RB, Engin E and Swolfs WM (2013) Plaxis 3D Reference Manual. Delft University of Technology and Plaxis BV, the Netherlands

Byrne BW and Houlsby GT (2003) Foundations for offshore wind turbines. Philosophical Transactions Royal Society of London A 361(1813): 2909-2930.

Byrne BW and Houlsby GT (2015) Helical piles: an innovative foundation design option for offshore wind turbines. Philosophical Transactions Royal Society of London A 373(2035): 20140081.

DNV (Det Norske Veritas) (2014) DNV-OS-J101: Offshore standard: design of offshore wind turbine structures. DNV, Norway. See http://diaviou.auth.gr/sites/default/files/pegatraining/Os-J101_201405.pdf (accessed 01/02/2017).

Fleming K, Weltman AJ, Randolph M and Elson WK (2009) Piling Engineering, 3rd edn. Taylor \& Francis, Abingdon, UK.

Gavin K, Doherty P and Tolooiyan A (2014) Field investigation of the axial resistance of helical piles in dense sand. Canadian Geotechnical Journal 51(11): 1343-1354.

Jaky J (1944) The coefficient of earth pressure at rest. Journal of the Society of Hungarian Architects and Engineers 78(22): 355-358.

Jeffrey JR, Brown MJ, Knappett JA, Ball J and Caucis K (2016) CHD pile performance: part I - physical modelling. Proceedings of the Institution of Civil Engineers - Geotechnical Engineering 169(5): 421-435, http://dx.doi.org/10.1680/jgeen.15.00131.

Karthigeyan S (2008) Numerical investigation of the effect of combined loading on the lateral response of piles in sand. Challenges and Applications of Mathematical Modeling Techniques in Building Science and Technology (CAM2TBST). Central Building Research Institute, Roorkee, India, pp. 420-429.

Karthigeyan S, Ramakrishna VV and Rajagopal K (2006) Influence of vertical load on the lateral response of piles in sand. Computers and Geotechnics 33(2): 121-131.

Karthigeyan S, Ramakrishna VV and Rajagopal K (2007) Numerical investigation of the effect of vertical load on the lateral response of piles. Journal of Geotechnical and Geoenvironmental Engineering 128(9): 764-774.

Knappett JA, Brown MJ, Brennan AJ and Hamilton L (2014) Optimising the compressive behaviour of screw piles in sand for marine renewable energy applications. Proceedings of International Conference on Piling \& Deep Foundations, Stockholm, Sweden. DFI, Hawthorne, NJ, USA, Article 1904, publication 100 (IC-2014).

Knappett JA, Brown MJ, Aldaikh H et al. (2015) A review of anchor technology for floating renewable energy devices and key design considerations. In Proceedings of 3rd International Symposium on Frontiers in Offshore Geotechnics, Oslo, Norway (Meyer V (ed.)). Taylor \& Francis, London, UK, pp. 887-892.

Knappett JA, Caucis K, Brown MJ, Jeffrey JR and Ball J (2016) CHD pile performance: part II - numerical modelling. Proceedings of the Institution of Civil Engineers - Geotechnical 
Engineering 169(5): 436-454, http://dx.doi.org/10.1680/ jgeen.15.00132.

Lauder K, Brown MJ, Bransby MF and Boyes S (2013) The influence of incorporating a forecutter on the performance of offshore pipeline ploughs. Applied Ocean Research Journal 39: 121-130.

Lee J, Prezzi M and Salgado R (2011) Experimental investigation of the combined load response of model piles driven in sand. ASTM Geotechnical Testing Journal 34(6): 653-667.

Madhusudan Reddy K and Ayothiraman R (2015) Experimental studies on behavior of single pile under combined uplift and lateral loading. Journal of Geotechnical and Geoenvironmental Engineering 141(7): 04015030

Matlock H and Reese LC (1960) Generalized solutions for laterally loaded piles. Journal of Soil Mechanics and Foundation Division ASCE 86(5): 63-91.

Meyerhof GG and Yalcin AS (1993) Behaviour of flexible batter piles under inclined loads in layered soil. Canadian Geotechnical Journal 30(2): 247-256.

Mosquera ZS, Tsuha CH, Schiavon JA and Thorel L (2015) Discussion of 'Field investigation of the axial resistance of helical piles in dense sand' 1. Canadian Geotechnical Journal 52(8): 1190-1194.

Mu LL, Huang MS, Zhang J and Feng CM (2015) Influence of vertical loads on the behavior of laterally loaded large diameter pile in sand. In Proceedings of 3rd International Symposium on Frontiers in Offshore Geotechnics, Oslo, Norway (Meyer V (ed.)). Taylor \& Francis, London, UK, pp. 729-734.

Perko HA (2009) Helical Piles: A Practical Guide to Design and Installation. Wiley, Hoboken, NJ, USA.

Phillips R and Valsangkar A (1987) An Experimental Investigation of Factors Affecting Penetration Resistance in Granular Soils in Centrifuge Modelling. Department of Engineering, Cambridge University, Cambridge, UK, Technical Report CUED/D-Soils/TR210.

Poulos HG (1971) Behaviour of laterally loaded piles: I - single piles Journal of Soil Mechanics and Foundation Division ASCE 97(5) 711-731.

Poulos HG and Davis EH (1980) Pile Foundation Analysis and Design. Wiley, New York, NY, USA.

Rajagopal K and Karthigeyan S (2008) Influence of combined vertical and lateral loading on the lateral response of piles. Proceedings of the 12th International Conference of International Association for Computer Methods and Advances in Geomechanics (12IACMAG), Goa, India, pp. 3272-3282.
Rosbjerg S and Gravesen H (2009) OWA Offshore Wind Farm Foundations, UK Round 3 Design Basis, Version 2. Grontmij Carl Bro.

Sakr M (2010a) Lateral resistance of high capacity helical piles - case study. Proceedings of the 63rd Canadian Geotechnical and 6th Canadian Permafrost Conference, Calgary, Alberta, pp. 402-412.

Sakr M (2010b) High capacity helical piles - a new dimension for bridge foundations. Proceedings of the 8th International Conference on Short and Medium Span Bridges, Niagara Falls, Canada, pp. 142-1-142-11.

Saleem Z (2011) Alternatives and Modifications of Monopiles Foundation or its Installation Technique for Noise Mitigation. TU Delft, Delft, the Netherlands.

Sanctis L and Russo G (2008) Analysis and performance of piled raft designed using innovative criteria. Journal of Geotechnical and Geoenvironmental Engineering 134(8): 1118-1128.

Sastry VVRN and Meyerhof GG (1994) Behaviour of flexible piles in layered sands under eccentric and inclined loads. Canadian Geotechnical Journal 31(4): 513-520.

Schanz T, Vermeer PA and Bonnier PG (1999) The hardening-soil model: formulation and verification. In Proceedings of International Symposium: Beyond 2000 in Computational Geotechnics, Amsterdam, the Netherlands (Brinkgreve R (ed.)). Balkema, Rotterdam, the Netherlands, pp. 281-290.

Skempton AW (1986) Standard penetration test procedures and the effects in sands of overburden pressure, relative density, particle size, ageing and overconsolidation. Géotechnique 36(3): 425-447, http://dx.doi.org/10.1680/geot.1986.36.3.425.

Thomsen F, Lüdemann K, Kafemann R and Piper W (2006) Effects of Offshore Wind Farm Noise on Marine Mammals and Fish. Biola, Hamburg, Germany on behalf of Cowrie Ltd 62

Tolooiyan A and Gavin K (2013) The base resistance of nondisplacement piles in sand. Part II: finite-element analyses. Proceedings of the Institution of Civil Engineers - Geotechnical Engineering 166(6): 549-560, http://dx.doi.org/10.1680/ geng.11.00101.

Tsuha CH, Aoki N, Rault G, Thorel L and Garnier J (2012) Evaluation of the efficiencies of helical anchor plates in sand by centrifuge model test. Canadian Geotechnical Journal 49(9): 1102-1114.

Zadeh NG and Kalantari B (2011) Performance of single pile under vertical and lateral load in sand, clay and layered soil. Electronic Journal of Geotechnical Engineering 16: 1131-1146.

Zhang DY (1999) Predicting Capacity of Helical Screw Piles in Alberta Soils. MSc thesis, University of Alberta, Edmonton, Canada.

\section{How can you contribute?}

To discuss this paper, please email up to 500 words to the editor at journals@ice.org.uk. Your contribution will be forwarded to the author(s) for a reply and, if considered appropriate by the editorial board, it will be published as discussion in a future issue of the journal.

Proceedings journals rely entirely on contributions from the civil engineering profession (and allied disciplines). Information about how to submit your paper online is available at www.icevirtuallibrary.com/page/authors, where you will also find detailed author guidelines. 